\title{
Retraction: Probabilistic assessment of earthquake damage and loss for the City of Tabriz, Iran
}

\author{
S. G. Hashemi ${ }^{1}$, H. Karimiyan ${ }^{2}$ \\ Department of Civil Engineering, Shahrekord Branch, Islamic Azad University, Shahrekord, Iran \\ ${ }^{1}$ Corresponding author \\ E-mail: ${ }^{1}$ hashemi.1369@yahoo.com, ${ }^{2}$ karaimiyan29@gmail.com
}

DOI https://doi.org/10.21595/mme.2018.19846

Check for updates

Publisher's note regarding paper

Hashemi S. G., Karimiyan H. Probabilistic assessment of earthquake damage and loss for the City of Tabriz, Iran. Mathematical Models in Engineering, Vol. 1, Issue 2, 2015, p. 43-53.

\section{The description of the retraction}

Retraction Date: March 31, 2018

Retraction Requested By: Editor in Chief and the Publisher

Retraction Type: Plagiarism

This paper is retracted because some sections partially or in some cases fully coincide with parts of the paper published in 2013 (listed below) without any permission from authors, or even citing the paper.

G. Ghodrati Amiri, N. Khoshnevis, S. Razavian Amrei Probabilistic assessment of earthquake damage and loss for the city of Tehran, Iran. Journal of Rehabilitation in Civil Engineering, Vol. 1, Issue 2, 2013, p. 10-23, https://doi.org/10.22075/JRCE.2013.9

The Publisher has checked the retracted paper for similarity issues using plagiarism detection software, however the mentioned paper was not listed in the similarity report. The similarity issues were raised by the authors of the paper published in Journal of Rehabilitation in Civil Engineering.

The Publisher tried to contact Hashemi S. G. and Karimiyan H. numerous times in order to explain the situation, but no answers were received.

Considering recommendations from the Committee on Publication Ethics (COPE) this case was clarified as plagiarism. 